\title{
Technical Quality Analysis of Trunk Pipeline
}

\author{
${ }^{1}$ Liya H. Fokeeva, ${ }^{2}$ Guzel R. Ganieva, ${ }^{3}$ Kimetova Ramilya, ${ }^{4}$ Arslanov Almaz \\ ${ }^{1-4}$ Kazan Federal University \\ Email: fokeeva.00@mail.ru
}

\section{Received: $20^{\text {th }}$ August 2019, Accepted: 30 ${ }^{\text {th }}$ September 2019, Published: $31^{\text {st }}$ October 2019}

\begin{abstract}
The current level of technology development concerning technical, informational and organizational services in the field of the linear part of trunk pipeline technical condition diagnostics has significantly increased the control reliability and productivity [1].

Thus, tens of thousands of defects, including those of an operational nature, are detected annually only via in-line inspection.

Since the start of the oil and gas industry development, the oil transportation system has undergone many changes [2]. The main type was pipeline transport, the facilities of which ensure the transfer of more than $85 \%$ of the oil produced in Russia. Such indicators are conditioned by a number of reasons. Here are some of them: the relatively low cost of pumping, short and uninterrupted delivery of products, the ability to transport several types of oil products at the same time, and others. The main pipelines are designed so that oil from the fields passes to main consumers and refineries through the main intermediate consumption points, as well as commodity products are exported [3].

The timely implementation of mandatory and recommended works will ensure the safety of the entire oil transportation system, and will also serve to develop the potential of this economic sector of the state. The system for oil, gas and oil product transportation is the combination of trunk pipelines.
\end{abstract}

\section{Keywords}

Station, Pipeline, Transport, Scraper, Launch-Reception Chamber

\section{Introduction}

The unified system of main oil pipelines (MOP) is the largest in the world, covering such a diverse territory. The development plan takes into account the need for modernization and repair of operating systems, the bulk of which was built more than 20 years ago [4]. The timely implementation of mandatory and recommended works will ensure the safety of the entire oil transportation system, and will also serve to develop the potential of this economic sector of the state. The main activities of oil transportation companies are the following ones [9]:

- Provision of services in the field of transportation of oil and oil products through the trunk pipeline system.

- Carrying out preventive, diagnostic and emergency repair work on trunk pipelines.

- Coordination of activities for the integrated development of trunk pipeline network and other pipeline transport facilities.

- Interaction with pipeline enterprises of various countries on the transportation of oil and oil products in accordance with intergovernmental agreements.

- Participation in scientific, technical and innovative development issue solution concerning pipeline transport, the introduction of new equipment, technologies and materials.

- Organization of work to ensure environmental protection in the areas of pipeline transport facility location. Oil, gas and oil product transportation system is a combination of trunk pipelines. An extensive network of such pipelines (oil, gas and oil product pipelines) is the main way of oil (99\%), oil product (50\%), natural, oil and artificial hydrocarbon gas (100\%) delivery from the regions of their production to internal and external consumers [5]. The main pipelines, unlike domestic, local and technological, are characterized by a long length, high throughput and connect the supplier of oil and gas products to the consumer. Due to the long extent, the pumping is carried out not by one, but by several stations located along the highway. The operation mode of such pipelines is continuous (short-term stops are random or associated with repair and restoration work) [5].

The main pipelines are laid more underground (especially in settlements, on the territories of large enterprises, transport hubs and structures), but it is permitted, with appropriate security, to lay on the ground in an embankment or on supports. The principles of trunk pipeline protection require the installation of security zones around pipelines.

The main pipeline is a difficult system that connects the pipeline itself with equipment for the purpose of oil and gas transportation; leading and intermediate oil pumping stations; tank farms; installation of electrochemical, fire and erosion protection against corrosion; power lines and technological communication lines; identification and signal signs and pointers, buildings and structures of the linear pipeline operation service [6].

The operation of pipelines means a set of actions for the transportation of oil and gas (reception, pumping, transmission), maintenance and repair. These actions are carried out by a licensed operating organization, and state regulatory authorities supervise compliance with regulatory and technical documents. The operating organization is required to provide:

- Safety of pipelines and equipment; 
- Reliable and uninterrupted operation of all structures and equipment;

- Set pumping mode;

- The development of regulatory processes;

- The reduction of resource losses (oil and gas, electricity, fuel, materials, etc.)

- Timely repair of equipment;

- Environmental safety of pipelines;

- Safe working conditions;

- Training of production personnel, their briefings, knowledge control concerning labor protection and industrial safety rules;

- Elimination of accidents, damage and their consequences;

- Accounting for oil and gas in relevant reporting documents;

- The safety of material assets at the facilities.

\section{Methods}

The duration of trunk pipeline operation is affected by the equipment of the pipeline with electrochemical protection means: with high-quality insulation, laying and backfilling of pipelines and further continuous protection against corrosion, a pipeline can be operated at maximum permissible levels for decades. Currently, the average age of gas pipelines is 25 years, and the average age of oil pipelines is 30 . Violation of the integrity of pipelines due to the violation of technology and standards concerning the production, installation and maintenance of pipes, the effects of natural phenomena can lead to accidents [5]. If damage to the pipelines is discovered, it is necessary to organize repair crews quickly.

The cavity of the main pipeline may contain foreign objects that have fallen during construction (soil, stones, electrodes and their remains, etc.), water accumulations, gas accumulations, paraffin deposits. Typically, the maximum amount of deposits is observed in the areas where the temperature of the oil flow is in the range of $20-28{ }^{\circ} \mathrm{C}$. The process of deposit formation on the walls of the pipes is as follows. When oil moves in a pipeline, it is cooled gradually, and at a certain temperature, solid hydrocarbons begin to precipitate from it. This process takes place both in the stream and in the coldest pipe wall [8]. Moreover, part of the paraffin crystals formed in the stream also deposits on the wall due to collisions. With the increase of speed under developed turbulent pumping conditions, the deposition rate of paraffin decreases. This is explained by the fact that, oil better holds paraffin crystals in suspension with increasing speed, and in addition, the possibility of washing off the deposited paraffin from the pipe wall increases. However, the thickness of the deposits decreases with Reynolds numbers less than 4000. The reason for this is that the lower the sliding speed of some fluid layers relative to others, the more time is required for the delivery of solid hydrocarbon molecules to crystallization centers [7].

The largest decrease in pipeline throughput due to waxing occurs during summer.

This is explained by the fact that, due to the lower oil heating temperature, the mass crystallization temperature of paraffin was higher than the final oil temperature, while in winter the ratio of these temperatures was the opposite. Cleaning is done when throughput is reduced by $3 \%$.

Deposits accumulated in the pipeline cavity during operation lead to throughput decrease [5]. The state of an existing oil pipeline cavity is assessed in order to determine the method of oil pumping, to remove water accumulation, in order to prevent the development of internal corrosion of pipelines. Assessment of the condition can be performed: extraordinary (unscheduled) evaluation is performed with an increase compared to the planned energy consumption, a decrease in throughput, a decrease in the effective diameter of the pipeline; - pre-diagnostic evaluation is performed to ensure the necessary degree of cleaning of the pipeline internal cavity, for in-line diagnostics conduct. The planning of oil pipeline cleaning is done by forming an annual plan and monthly work plan on its basis taking into account the requirements for the frequency of cleaning; - the annual plan for in-line diagnostics; - the need for targeted cleaning after repair work in accordance with the plan for stopping the pipeline.

It is recommended that oil is pumped once a week according to the "through tanks" scheme at a speed of more than 1.5 $\mathrm{m} / \mathrm{s}$ for two hours at least. If there are reserve lines for underwater crossings over rivers and swamps, loops and bypass lines at the oil pipeline sections, it is first planned to clean them, and then to clean the section itself. Loops, reserve lines and the jumpers between parallel pipelines should be disconnected from the main pipeline for the period of passage of treatment devices, calibers and diagnostic tools. At present, one of the defining requirements for main oil pipelines is the provision of their reliable, safe operation during long periods of work. The need to fulfill this requirement is dictated by the high level of costs for the construction and repair of pipelines, serious environmental problems during accidents, and toughening of legislative standards for environmental protection. Operational experience has shown that for pipelines with long service life, the traditional system of maintenance and repair was not able to prevent the occurrence of major accidents with severe consequences for the population and the environment. As the main method of oil pipeline reliability increase, overhaul was used with a complete replacement of pipes and insulation coating in large sections. This method was not effective enough due to the small volumes of repairs, and the limited information on the basis of which a site was selected for repair. The main means of such information obtaining were control pits and the measurements of electrochemical protection potentials [2]. The conduct of hydraulic tests with high pressure was also of a limited nature, since it was associated with high costs, the decommissioning of the pipeline for a long time, and also created environmental problems when water was removed from the pipeline contaminated with oil. It became 
obvious that the traditionally applied methods for oil pipeline reliability provision have exhausted their capabilities and it is necessary to look for a new solution to this problem. Thus, a strategic course was taken to create a fundamentally new security system and long-term operation of oil trunk pipelines. The concept of this system is based on the operability restoration, without disrupting the normal operation of the pipeline, of only those defective local zones of the pipeline where it was reduced to a dangerous level [5].

The main provisions of the concept are the following ones:

- Defects of any origin should be identified by the means of in-line diagnostics and eliminated during the repair before they get a dangerous development;

- In-pipe diagnostics should be carried out throughout the entire life cycle of the pipeline with a certain frequency;

- According to the data concerning the parameters of defects on the basis of strength calculations, the assessment of their danger should be performed;

- On the basis of data concerning the danger of defects, the characteristics of oil pipeline distribution by distance, repair programs should be developed or safe operating modes should be assigned.

A fundamentally new and key aspect of the safe and long-term operation system was the use of in-line diagnostics, which required the use of special equipment and technologies. The necessary efficiency of in-line diagnostics is ensured thanks to the principles laid down in its foundation. The main one is high resolution, which allows you to measure defects and assess their danger according to the results of strength calculations. This makes it possible to repair only that part, which is limited to a certain number of defects that pose a real threat to the integrity of the pipeline.

Since each type of diagnostic shells is designed to identify one or more types of defects, to identify the entire gamut of defects, it is necessary to use a complex of shells. For this purpose, a four-level integrated diagnostic control system is implemented, providing the definition of:

- Defects in the geometry of the pipeline;

- Defects in the metal of the pipe wall (corrosion ulcers, scratches), as well as intra-wall defects such as delaminations and inclusions;

- Transverse cracks and crack-like defects in the pipe body on annular welds;

- Longitudinal cracks and crack-like defects in the pipe body on longitudinal welds.

First of all, it is required to carry out the control of the first level - for the presence of dents and corrugations, which cause the narrowing of the pipe cross section. Shells-profilers are used for this. During the priority of control determination concerning other types of defects, priority is given to those of them that during the previous period of operation caused most of the failures. To control the defects of the second level - metal losses, delaminations, inclusions, ultrasonic projectiles-flaw detectors are used.

At present, flaw detection shells of the third level of diagnostics - high-resolution magnetic shells have been commissioned, which are primarily tasked with identification of defects in ring welds.

It should be noted that the main link in the diagnostic system is the detection of cracks. It plays a crucial role in reliability provision of aging oil pipelines. To ensure the operation of shells, inspections of the flaw detector before run, copying and assessing the quality of the data obtained during the diagnosis, a large number of auxiliary equipment is used:

- The launch-reception system for storing diagnostic shells in the launch chamber and their retrieval from the receiving chamber;

- Service and transport trays for shell transportation and maintenance;

- Thermocontainer for flaw detector transportation during the cold season;

- Special telescopic traverse, providing lifting of multi-sectional shells;

- Set of electronic equipment.

The conduct of in-line diagnostics has fundamentally changed the approach to repair. The essence of the new approach lies in the fact that the output of sections for repair began to be determined individually, taking into account the results of in-line diagnostics. Diagnostic results show that the distribution of defects along the pipeline is very uneven: $75 \%$ of the defects are located separately from each other, the remaining $25 \%$ are in the areas with dense defects. This made it possible to proceed to selective repair. Selective repair according to the actual condition allows to increase the total length of the repaired pipelines by an order of magnitude and maintaining it with the same capacity as the in-line diagnostics.

\section{Results}

The devices of launching and receiving chambers (LRC) for cleaning and diagnostic tools are intended for periodic launch into the pipeline and receiving in-pipe shells - flaw detectors, cleaning pistons, scrapers, separators and other means from it.

Operating temperature - from $-60{ }^{\circ} \mathrm{C}$ to $+80^{\circ} \mathrm{C}$. The calculated seismicity of the camera installation area is up to 9 points. The gearbox is easy to operate. It allows you to open the shutter in 10-20 minutes and provide access to the internal cavity for a flaw detector, a cleaning piston installation, etc. The length of the camera body allows you to use any modern diagnostic tools. 
Straight cuts are mounted on the upper part of the starting and receiving devices, to introduce flushing water or compressed air, to bleed the gas-air mixture to fill the devices with oil, to dump dirty water with garbage into the sump. The start-up and reception chamber consists of the following components: the start-up and reception chamber of the CDS (cleaning and diagnostics system) with spare nozzles and technical piping, connected to the main line through locking devices; a system for monitoring and control the processes of CDS receiving and starting; CDS storage point; technological pipelines and tanks to receive contaminated condensate; the devices for CDS loading and removing from launch and reception chambers; drainage system consisting of several valves, drain tank and leakage pump; technological wells.

If there is no need to start or receive CDS or another in-pipe projectile, all shut-off valves are in the closed position, the entire oil flow flows through the main pipeline system.

\section{Discussion}

The maintenance of cleaning devices is carried out after each pass in accordance with the requirements of the instruction manual for a specific device. When you perform maintenance use the following tools: - tape measure to measure the dimensions of the components; - vernier caliper to determine the amount of wear of polyurethane discs; torque wrenches to check the tightening forces of the fastening bolts; - sets of wrenches, ring spanners and ring heads to work with fasteners. It is necessary to observe the timing of the verification of measuring instruments in order to avoid distortion of the measurement results. When you attach threaded connections, it is forbidden to: - put gaskets between the jaws of keys; - use pipes and other objects as levers; - use nuts and bolts with damaged edges.

The maintenance of cleaning devices consists in monitoring the condition of the wearing elements of the scraper and their replacement in case of wear. Wear elements include: - polyurethane cleaning discs; - drive wheels; - brushes; cuffs; - grounding plates. For cleaning discs, the side that will clean the pipe is subject to wear assessment. Using a tape measure, the percentage of disk wear is determined, which indicates how much of the disk edge thickness is lost. The thickness of a new disk makes $100 \%$. If the edge of the disc is worn less than $25 \%$, reuse of the cleaning disc is allowed.

\section{Conclusions}

The goal of a supervisory control and management system development is to implement the ability to provide supervisory control and automated control of all existing technological objects effectively and fully, collect data on their status and obtain all necessary reporting documents, as well as the possibility of further expansion of the system functionality if necessary. The most widely used in automation systems used in transport construction are the sensors that convert non-electric quantities to electrical, since the output signal (current, voltage) can be recorded, transmitted over a distance and thereby control the production process remotely.

The main characteristics of the sensor are static response and sensitivity.

\section{Summary}

The design, installation and operation of the chambers must comply with the requirements of the relevant standards. The camera must be designed for transportation by rail, road and water transport in accordance with the requirements of the rules for the carriage of goods in force on each type of transport. Safety requirements for the transportation and storage of cameras:

a) The transportation and storage of cameras should be carried out taking into account all safety requirements provided by the camera manufacturer;

b) After the expiration of the specified storage period, the chamber must be re-preserved;

c) The transportation of cameras should be carried out in accordance with the rules applicable to specific modes of transport;

d) Loading, unloading, transportation and storage of chambers should be carried out by certified personnel in compliance with safety requirements when these works are performed.

The installation and fastening of the camera on the vehicle should exclude the possibility of mechanical damage and contamination of the inner surfaces of the cameras and the ends of the pipes processed for welding to the pipeline.

The potential danger of the possible negative impact of large-scale and technologically complex activities on the environment arises from the transport of oil. For this, related work is carried out in such a way that the requirements of state legislation, international treaties, standards and rules in the field of environmental management, environmental protection and environmental safety are met. Purpose: - continuous improvement of environmental activities and environmental management; - reduction of the negative impact on the environment by increasing the environmental safety of pipeline transport facilities, reducing emissions, discharges of pollutants into the environment and industrial waste; -Taking into account the long-term environmental consequences of the pipeline oil transport operation; - the transparency of environmentally significant information on activities.

\section{Acknowledgements}

The work is performed according to the Russian Government Program of Competitive Growth of Kazan Federal University. 


\section{References}

1. Ershov K.E. The structure of maintenance and repair of modern technological equipment of a machinebuilding enterprise on the basis of working time resource criterion. - Kazan: KAI, 2006. - 180 p.

2. Electronic resource: https://www.pwc.ru/ru/oil-and-gas/pdf/oil-gas-2018

3. Doroshev Yu.S., Nestrugin S.V. Progressive technology for rotating equipment maintenance / Scientific Electronic Library "Cyberleninka" / Electronic resource: https: //cyberleninka.ru/article/n/progressivnyetehnologii-tehnicheskogo-obsluzhivaniya-vraschayuschegosya-oborudovaniya, 2008. - pp. 256-260.

4. Zhukov A.S. Prediction of the technical condition of large diameter gas pipelines based on the results of surveys / Cyberleninka Scientific Electronic Library / Electronic resource: https://cyberleninka.ru/article/n/progressivnye-tehnologii-tehnicheskogo-obsluzhivaniya-vraschayuschegosyaoborudovaniya, 2008. - pp. 261-266.

5. Arslanov A.R. Technical re-equipment of the Volodarskaya oil pumping station / Graduation work. - Kazan: Kazan Federal University, 2019. - 67 p.

6. Nekhaev G.A. Design and calculation of steel cylindrical tanks and low pressure gas holders. - M.: Nedra, 2005. - 213 p.

7. Belenya E.I. Metal structures: Textbook for high schools. - 6th ed., revised and added. / E.I. Belenya, V.A. Baldin, G.S. Vedenikov - M: Nedra, 1980. - 560 p.

8. GOST 14782-86. Non-destructive control. Welded joints. Ultrasonic methods.

9. SP 36.13330.2012. Main pipelines / Ministry of Construction of Russia. - M.: GUPTSPP, 1997. - 60 p. 